\title{
Modelling of Energy and Water Supplies in Hotels in Lanzarote and Fuerteventura with and Without Desalination Plant (SWROP)
}

\author{
Francisco Javier Diaz Perez ${ }^{1 *}$, David Chinarro ${ }^{2}$, Adib Guardiola Mouhaffel ${ }^{3}$, \\ Ricardo Diaz Martin ${ }^{4}$ and Rosa Pino Otin ${ }^{1}$ \\ IInstitute of Environment, Faculty of Health Sciences, University San Jorge, Spain; fjdiazp@usj.es, rpino@usj.es \\ ${ }^{2} \mathrm{~S} c h o o l$ of Architecture, University San Jorge, Spain; dchinarro@usj.es \\ ${ }^{3}$ General Manager Grupo Marco Senegal, PhD Professor (Cela Open institute) Aggregate center of \\ Camilo Jose Cela University; guardiolaadib@gmail.com \\ ${ }^{4}$ Distance university of Madrid (UDIMA), Madrid, Spain; ricardo.diaz.m@udima.es
}

\begin{abstract}
Objectives: This article presents a comparative study of energy and water consumption in four-star hotels in the Canary Islands (Spain), specifically on the islands of Fuerteventura and Lanzarote, with and without desalination sea water reverse osmosis plants (SWROP), of order to define a pattern of consumption based on the average occupancy rates of different establishments. Methods/Statistical Analysis: The method used for regression calculations of the data obtained has been, initially the data collection and filtration, perform the mean arithmetic of the data according to the intervals calculated, perform calculations and generate the correlation graphs of the different models, change the occupancy rates to a percentage and use all the values for the total calculation as if it were a single hotel, calculate the final model of energy and water consumption for establishments, and create a valid algorithm using the calculated regression models. Findings: We demonstrate the validity of the potential and polynomial models of regression used to calculate the approximate values for consumption of water, electricity and energy, valid for most of the hotels with an average occupancy rate of between $40 \%$ and $120 \%$, which are typically the average occupancy rates for hotels in the Canary Islands during various months of the year. Through a calculated and demonstrated system of analysis, approximate simulations of consumption can be performed for hotels with the same or similar characteristics and modelling of reduced energy consumption can be performed by simulating occupancy values to test the level of reduction. Application/Improvements: The article concludes with the functions for the approximate calculations of energy consumption, electricity and water per guest, per day for hotels with similar characteristics to those in the study.
\end{abstract}

Keywords: Energy, Efficiency, Hotels, Modelling, nZEB, SWROP, Water

\section{Introduction}

At a global level, two-thirds of emissions come from energy consumption, the tourism sector-being a major consumer of energy-contributing $5 \%$ due to the inefficiency of energy consumption that occurs in that sector. The tourist accommodation sector represents more than $20 \%$ of emissions from tourism and energy consumption from tourism overall' is equivalent to $1 \%$ of global emissions. For this reason, hotel buildings, which operate in geographical areas with a high concentration of tourism and intensive seasonal use, pose a major challenge to the sustainability of tourist destinations.

The European Union has set a goal of reducing energy consumption, as well as $\mathrm{CO}_{2}$ emissions, by $20 \%$ by 2020 in comparison to 1990 levels, stipulating that $20 \%$ of total energy consumption must come from renewable sources and giving much importance has been placed on energy efficiency through the publication of several directives on it, as the directive directive 2010/31/EU 月 on energy efficiency in buildings, investigated their application in buildings in one study and directive 2012/27/EU on

*Author for correspondence 
energy efficiency, which also highlights the importance of promoting energy efficiency in buildings, setting a time to achieve Zero Energy Buildings (ZEB) or near to Zero (nZEB), this being an obligation in new constructions for the year 2018 general government and by 2020 the other buildings, which has been studied their application in Lithuania月,

The archipelago of the Canary Islands, belonging to Spain and located in the Atlantic Ocean near the coast of southern Morocco and the Sahara, north Africa, between coordinates $27^{\circ} 37^{\prime}$ and $29^{\circ} 25^{\prime}$ north latitude and $13^{\circ} 20^{\prime}$ and $18^{\circ} 10^{\prime}$ west longitude, with a total area of $7447 \mathrm{~km}^{2}$ and an oceanic subtropical climate, has stable yearround temperatures mitigated by the sea in winter and in summer by trade winds. Currently the tourism sector in the Canary Islands represents $31 \%$ of the archipelago's GDP and generates 36\% of employment on the islands it being the main engine of the economy. It is the main engine of the economy and its labour mobility as demonstrated in the study off on the labour market in the Canary Islands. At this location, there are 626 hotels that offer more than 244,000 hotel beds?. Annually, around $13,000,000$ tourists visit and produce more than 100 million overnight stays in hotels on the islands. Energy consumption for hotels in the tourism sector accounts for $15 \%$ of total electricity consumption 1 and $11 \%$ of water consumption 10 , with respect to the overall consumption of the islands. Taking into account the importance of tourism for the Canary Islands, the search for models of energy consumption and water sustainability is essential and valid for implementing energy efficiency strategies in hotels, which has become an essential aspect of European strategy for sustainable growth in 2020, and one of the most profitable ways to strengthen the security of energy supplies, as well as reduce emissions of greenhouse gases and other pollutants. It is very important to know the distribution of energy consumption in hotels so that it can be shown where improvements can and should be made in order to make reductions. Distribution varies according to geographical area and category of hotel, as can be seen by studies conducted in several countries, for example: in Britain, where the typical distribution is $47 \%$ on heating and 20\% in Domestic Hot Water (DHW) in Greece, where the typical distribution is $35 \%$ on heating, $15 \%$ on refrigeration, and $22 \%$ on DHW hotels in the Balearic Islands is between $22 \%$ for DHW , cooling $14 \%$ heating and $21 \%$, and the Canary Islands, where, due to its climatic characteristics, climatization is reserved mainly for air conditioning, with consumption at $31 \%$,and, in second place, DHW at $22 \%$ Tourist associations, along with several universities, have conducted various studies on the consumption of hotels. The International Tourism Partnership (ITP), in conjunction with Cornell University, has published the results of the study "Cornell Hotel Sustainability Benchmarking” (CHSB) ${ }^{\text {l }}$ to provide points of reference to hotels regarding energy and water consumption, and worldwide carbon footprint references for different types of establishments in various countries. The World Tourism Organization (UNWTO) has launched the project "Hotel Energy Solution", creating the E-Toolkit', a tool that allows small and medium-sized European companies in the hotel accommodation sector to make a comparative assessment of energy consumption, efficiency and carbon footprint, with similar companies on the continent. The Spanish Confederation of Hotels and Tourist Accommodation (CEHAT) and the Hotel Technological Institute (ITH) conducted an investigation of hotel consumption using the bench hotel mark tool, which generated a comparative report with hotels with similar characteristics, comparing energy and water consumption with hotels in Madrid and the Canary Islandst 1 , but without creating a reproducible model for other hotels. All these studies give typical values, but have not generated reproducible models using occupancy as an indicator, which is paramount in actual tourist establishments.

Other research has been carried out by the scientific community, such as that performed in 2009 19 whereby a study of 29 energy intense hotels was conducted in Singapore, checking their linear correlation with various parameters of different hotels, such as the average monthly occupancy rate and average temperature. The average consumption of the hotels stood at $427 \mathrm{kWh} / \mathrm{m}^{2} /$ year. Heterogeneous samples of hotels concluded with the need to group the data into more homogeneous hotels for utility models in simulating energy consumption. In 201220 performed a comprehensive study on the basis of 200 hotels in four categories, checking the levels of energy consumption based on the category of hotels, among other factors. Energy consumption was between 280 and $143 \mathrm{kWh} / \mathrm{m}^{2} /$ year and average consumption per occupied room was between 26,7 and $9,4 \mathrm{kWh} /$ room/ nigth with $84 \%$ of the energy consumed being electricity. In 2012 12 , conducted a study on the classification of hotels in Greece for their energy consumption, according to the climatic zone and type of hotel, in which they took into 
account the size of the hotels but not their occupancy rates. The study in 20072 -roughly 184 hotels from the Hilton and Scandic chain in Europe - created a model of energy and water consumption in these hotels, taking into account multiple variables and modelling them by linearization of annual consumption. When basing a study on heterogeneous hotels, values are very generic and hardly usable for modelling all hotels, since there are large variations between them. In the study in 2011 月, to model water consumption in Acapulco, he found that the logarithmic model was the most appropriate for consumption of this type. In 2014 4 , investigated the modelling of water consumption in hotels through regression models in order to obtain a hyperbolic model of water consumption in hotels of the type investigated here. In investigations $2^{2}$ on the impact of tourism by type of accommodation, it means data for different countries and a global estimate is obtained per bed per night use 36 $\mathrm{kWh} / \mathrm{bed} /$ night, with consumption water through very uneven, with values between 100 to 2000 l/bed/night so cannot generate reliable means of water consumption per customer per day.

Data published by the major chains should also be taken into account, since they provide general data on energy and water consumption in their hotels, motivated by environmental certifications and their corporate environmental responsibility policies, which can be useful for checking the average consumption of different establishments comparatively, albeit without any model of consumption or grouping of hotels with similar characteristics. Examples of annual data published include the $\mathrm{NH}$ hotel chain, which gives indicators for occupied rooms of $3001 /$ day/room and energy consumption of $51.43 \mathrm{kWh} /$ day/roomer or the Riu hotel chain, with shows an average consumption per guest of $371 \mathrm{l} /$ day/guest and electricity of $15.31 \mathrm{kWh} /$ day/guest 2 ]

For this research, we focused on hotels in the Canary Islands, specifically on 4-star hotels, both with and without desalination plants to provide their own water, on the islands of Fuerteventura and Lanzarote. These two destinations have an average of 2.3 and 2 million tourists a year and 18.7 and 16.5 million overnight stays respectively. The reason that the study focuses on 4-star hotels, is that they represent more than $55 \%$ of the hotels in the Canary Islands and more than $70 \%$ of the rooms with which it is possible to realize an approximation of the consumption of most of the hotels on the islands.

\section{Experimental}

The data obtained from the corporate departments of the hotels from this study of total energy, water and electricity consumption, and number of guests staying a night (=overnight stays), was reviewed alongside the technicians responsible for each establishment, filtering out erroneous data - due mainly to failure to collect it or other chance events outside of normal operations (e.g., water leaks, renovations of facilities, breakage, etc.). With this list of definitive data, already filtered and reviewed, the calculation was performed for the histogram of the resulting data, generating the characteristic points grouped by frequency ranges. To calculate optimal ranges, the Sturges' formula for was used, which gives us the number of intervals depending on the amount of data obtained.

The next step was to perform the grouped distributions by intervals calculated, and once the values were grouped, the arithmetic mean of the data was performed in order to obtain the different characteristic points of consumption and perform the correlation calculations. The values are ordered by daily guest occupancy rates, which gives us a more accurate correlation than classic systems of monthly or annual consumption, because in this way, errors due to the different number of days in a month - which would provide an error of 6\% in February and 3\% in the months containing 31 days - are annulled, obtaining a distribution of values more tightly adjusted to their real values. With the data obtained from hotels, the calculations for total energy, electricity and water costs per guest per night were performed.

To test what kind of correlation resembled the models of consumption the most, correlation calculations were performed for linear, exponential, logarithmic, and polynomial of the second degree and potential models, testing their coefficient of determination and calculating their modelling function.

- Linear Regression whose shape fits:

$y=a x+b$

- Exponential Regression whose shape fits:

$y=a e^{b X}$

- Logarithmic regression whose shape fits:

$y=a \ln x+b$

- Second order polynomial regression whose shape fits: $\quad y=a+b x+c x^{2}$

- Power Regression whose shape fits: $y=a x^{b}$ 
The calculation of the values to find the function of the line of different value matrices was performed by

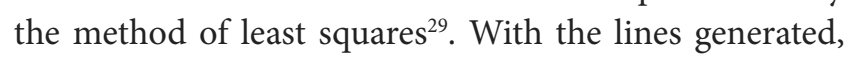
calculation of the correlation between the values can be performed, which indicates the degree of dependence between two variables, so we used the correlation coefficient of Karl Pearson" To interpret the correlation coefficient of Karl Pearson, it must be taken into account that its value ranges between 1 and -1 . Values closer to 1 imply a perfect positive linear relationship and -1 a perfect negative relationship. Values closer to 0 indicate a lower linear relationship?.

To test the correlation between the data, the coefficient of determination $\mathrm{R}^{2}$ was used to interpret the proportion or percentage of variation in the dependent variable, which is explained by the variation in the independent variable, i.e., the percentage of values that fit with the

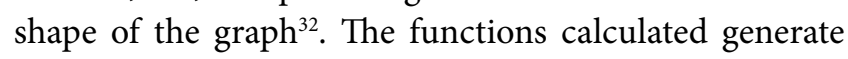
the various energy and water consumption graphs to test their shape and to generate a valid energy model.

This same methodology was used to calculate the correlations of all hotels for different total water, electricity and energy consumption levels. With data from all the establishments, and due to the different maximum capacities of each hotel, guests had to be averaged as a percentage of occupancy, which was necessary to make the relative comparison of the average daily occupancy rate and work with the data from all hotels as if they were a single establishment in order to generate the corresponding function for hotels of similar characteristics.

Figure 1 exhibits schematically the workflow that was followed to perform the correlation calculations, where a summary of the steps taken can be seen as follows: 1. Data collection and filtration, 2. Perform the mean arithmetic of the data according to the intervals calculated, 3. Perform calculations and generate the correlation graphs of the different models, 4 . Change the occupancy rates to a percentage and use all the values for the total calculation as if it were a single hotel, 5. Calculate the final model of energy and water consumption for establishments, and 6 . Conclusions.

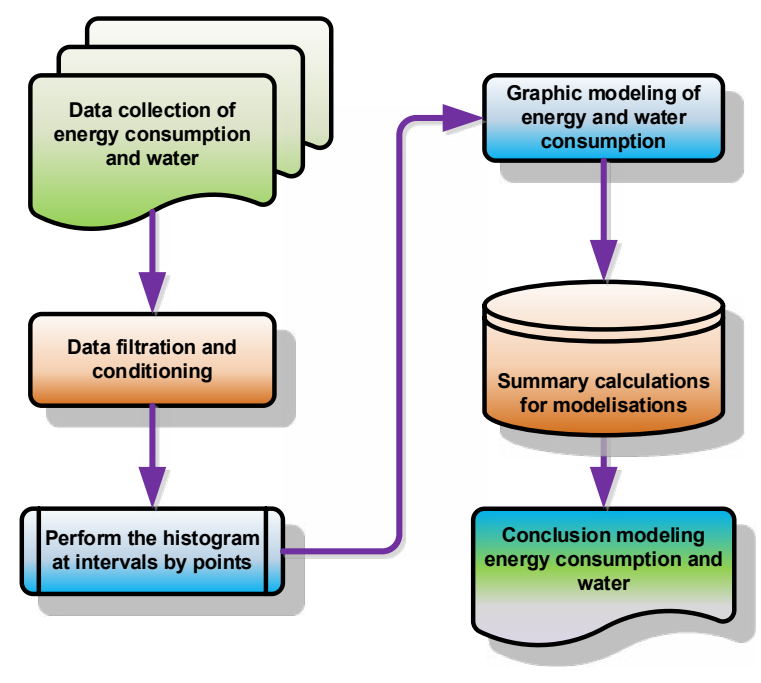

Figure 1. Diagram of the workflow for the research work. Source: Original.

To carry out the study of consumption in hotels, we chose several characteristic hotels in the Canary Islands, located on the eastern islands of Fuerteventura and Lanzarote, which have a peculiarity that distinguishes them from other hotels on other islands: their $100 \%$ reliance on desalinated water, due to the absence of hydrological resources for water distribution for general consumption on these islands. The hotels studied differ according to the way they supply water for human consumption, which is by producing water through a desalination Sea Water Reverse Osmosis Plants (SWROP) either located on the premises and belonging to the hotel or through a public water supply from a municipal plant located externally.

In the search for hotels with homogeneous characteristics, facilities were chosen that were less than 30 years old, had a 4-star rating, and fitted into the category 'holiday establishment', which implies a type of tourism where more of the hotel is enjoyed, such as the continual use of restaurants and swimming pools for the duration of the stay. All establishments have swimming pools and air conditioning, not counting heating. The gardens of the hotels are irrigated with desalinated or reclaimed water, which is motivated by the possibility of having 
Table 1. Details of facilities and characteristics of hotels studied

\begin{tabular}{|c|c|c|c|c|c|c|c|}
\hline \multicolumn{2}{|l|}{ DATES } & \multirow{2}{*}{$\begin{array}{c}\text { HPE } \\
\text { Fuerteventura }\end{array}$} & \multirow{2}{*}{$\begin{array}{c}\text { HT } \\
\text { Fuerteventura }\end{array}$} & \multirow{2}{*}{$\begin{array}{c}\text { ESA } \\
\text { Fuerteventura }\end{array}$} & \multirow{2}{*}{\begin{tabular}{c|} 
ECA \\
Fuerteventura
\end{tabular}} & \multirow{2}{*}{$\begin{array}{c}\text { HTI } \\
\text { Lanzarote }\end{array}$} & \multirow{2}{*}{$\frac{\text { MSL }}{\text { Lanzarote }}$} \\
\hline GENERAL & Location & & & & & & \\
\hline & Construction date & 2.000 & 2.004 & 2.003 & 2.007 & 1.997 & 1.988 \\
\hline & Land area & 30.000 & 34.879 & 27.163 & 34.670 & 38.622 & 26.163 \\
\hline & Constructed area & 25.912 & 31.132 & 22.710 & 28.307 & 34.112 & 24.507 \\
\hline & Rooms & 333 & 354 & 266 & 346 & 329 & 343 \\
\hline & Beds & 678 & 710 & 532 & 692 & 658 & 718 \\
\hline & Garden area & 8.000 & 11.000 & 6.000 & 14.000 & 8.000 & 5.000 \\
\hline & Water source & SWROP & SWROP & Public supply & Public supply & SWROP & SWROP \\
\hline & Irrigation source & SWROP & SWROP & Recycled & Recycled & SWROP & SWROP \\
\hline \multirow[t]{8}{*}{ POOLS } & No Freshwater & 2 & 1 & 2 & 1 & 8 & 1 \\
\hline & Area $\mathrm{m}^{2}$ & 572 & 240 & 702 & 589 & 1.160 & 1.084 \\
\hline & Volume $\mathrm{m}^{3}$ & 765 & 266 & 891 & 706 & 1.135 & 1.727 \\
\hline & No Climatized pool & 1 & 3 & 1 & 2 & 2 & 2 \\
\hline & Heating system & Electricity & AC Recovery & Electricity & Electricity & Electricity & $\begin{array}{l}\text { Solar } \\
\text { panels }\end{array}$ \\
\hline & kW heating & 38 & 378 & 100 & 135 & 25 & 95 \\
\hline & Area $\mathrm{m}^{2}$ & 86 & 232 & 331 & 439 & 85 & 120 \\
\hline & Volume $\mathrm{m}^{3}$ & 130 & 240 & 298 & 487 & 95 & 110 \\
\hline \multirow[t]{2}{*}{ Hot Water DHW } & Combustible & LPG Propane & LPG Propane & Diesel oil & Diesel oil & $\begin{array}{c}\text { LPG Propane } \\
+ \text { Diesel oil } \\
\end{array}$ & Diesel oil \\
\hline & kW heating & 537 & 650 & 800 & 1.000 & $272+200$ & 450 \\
\hline \multirow[t]{3}{*}{ Renewable energy } & Biomass heating $\mathrm{kW}$ & & & & & 270 & \\
\hline & No Solar panels & & & & & 168 & 92 \\
\hline & Solar panels $\mathrm{m}^{2}$ & & & & & 340 & 795 \\
\hline \multirow[t]{2}{*}{ Air Conditioner } & HVAC System & 1 & 2 & 2 & 2 & 1 & 1 \\
\hline & $\begin{array}{l}\text { kW Total HVAC } \\
\text { chillers }\end{array}$ & 344 & 828 & 792 & 804 & 485 & 450 \\
\hline \multirow[t]{2}{*}{$\begin{array}{l}\text { Desalination } \\
\text { SWROP }\end{array}$} & $\begin{array}{l}\mathrm{kW} \text { Power }(\text { feed }+ \\
\text { plant })\end{array}$ & 65 & 65 & & & 52 & 120 \\
\hline & Production $\mathrm{m} 3 /$ hour & 12 & 12 & & & 11 & 18 \\
\hline Years of date & & 2010-2013 & 2010-2015 & 2007-2012 & 2007-2012 & 2010-2015 & 2010-2015 \\
\hline
\end{tabular}

their own treatment plant or external supply of reclaimed or desalinated water, since not all establishments have the possibility of irrigating with reclaimed water. The modelling calculations were performed regardless of the irrigation methods used in each hotel.

The hotels studied do not have the facilities to generate their own electricity, either for their own consumption or for sale, except for replacement generators in case of power failure from the grid, nor do they have their own cogeneration equipment. All electricity comes through an external supply network, being, in all cases, medium voltage with transformers located within the hotel facilities. Other fuels and power generation systems used by hotels, for which data are available are: LPG propane, diesel, biomass pellets and thermal solar panels.

Consumption data for the hotels was obtained between 2007 and 2015, depending on the facilities, with minimum values per hotel of 4 years and maximum of 6 years. During the years of study, diesel boilers have been replaced with biomass boilers, producing similar yields and allowing equivalent calculations to be performed by transferring all combustibles to the same unit of energy, i.e., kWh.

\subsection{Data Analysis}

Table 1 shows the general data of the establishments 
studied, with their main characteristics and facilities being presented. The low use of renewable energy can be observed, present only in a few establishments for the heating of water for human consumption (DHW), as well as the lack of heating facilities. Due to the data protection of the hotels, we refer to each hotel with a code.

In considering a study of hotels with similar capacities and facilities, all feature gardens, swimming pools and have air conditioning in all rooms and public areas (restaurants, bars and lounges). The need be able to generate their own supply of water through desalination SWROP is also verified where there is an absence in the public supply, as is the case in some areas of the islands in this study, so it is necessary that hotels have their own desalination plants SWROP. With the main data from the hotels, a comparison was performed to check the average values of the facilities listed in Table 2. In this comparison of different facilities, the homogeneity of establishments can be checked.

Hotels in the Canary Islands, mainly those in the eastern islands of Fuerteventura and Lanzarote, have the peculiarity that they do not need heating in winter. The average winter temperatures do not require the use or installation of heating systems, which reduces the average consumption during the winter months, air conditioning not being required in most establishments either. The average temperature of the coldest months of December, January and February is close to $18^{\circ} \mathrm{C}$, with a minimum average of $16^{\circ} \mathrm{C}$ and a maximum of $20^{\circ} \mathrm{C}^{\text {月 }}$, making heating and air conditioning unnecessary.

\subsection{Consumption Water Performance}

To perform the calculations of water consumption, the peculiarity of these establishments must be taken into account, counting two extra types of consumption that are independent of hotel occupancy and operations. These consumptions are the replacement of swimming pool water and the irrigation of gardens, which have been studied independently.

Consumption from irrigation has not been taken into account in the calculations of the total water consumption of the hotels, since irrigation water can be of two types: purified water which has specific rules 月 $^{3}$ for its implementation, which was studied and compared with other European countries in 2015 5 and water for human consumption 3 , both of which are incompatible with each other. Irrigation costs in respect to total water consumption can be seen in Table 3, reaching an average expenditure at $12 \%$ of total water consumption. Given the total surface area of the gardens, irrigation consumption is calculated as $\mathrm{m} 2$ of garden, with an average of $2.67 \mathrm{l} / \mathrm{m} 2$ and a standard deviation of $0.6 \mathrm{l} / \mathrm{m} 2$.

Table 2. Main indicators of the hotels studied

\begin{tabular}{lcccccccc}
\hline INDICATORS & HPE & HT & ESA & ECA & HTI & MSL & Average & Typical deviation \\
\hline $\mathrm{m}^{2}$ Construction / rooms & 78 & 88 & 85 & 82 & 104 & 71 & 85 & 11 \\
$\mathrm{~m}^{2}$ Gardens / rooms & 24 & 31 & 23 & 40 & 24 & 15 & 26 & 9 \\
\% Gardens / land area & $27 \%$ & $32 \%$ & $22 \%$ & $40 \%$ & $21 \%$ & $19 \%$ & $27 \%$ & $8 \%$ \\
$\mathrm{~m}^{2}$ Pools / rooms & 2,0 & 1,5 & 3,9 & 3,0 & 3,8 & 3,5 & 2,9 & 1,0 \\
$\mathrm{~m}^{3}$ Pools / rooms & 2,7 & 1,6 & 4,5 & 3,4 & 3,7 & 5,4 & 3,5 & 1,3 \\
$\mathrm{~kW}$ Heating water / rooms & 1,6 & 1,8 & 3,0 & 2,9 & 1,4 & 1,3 & 2,0 & 0,7 \\
$\mathrm{~kW}$ AC / rooms & 1,0 & 2,3 & 3,0 & 2,3 & 1,5 & 1,3 & 1,9 & 0,7 \\
\hline
\end{tabular}

Table 3. Total consumption, percentages and garden surface area for irrigation water

\begin{tabular}{lccccccc}
\hline TYPE & HPE & HT & ESA & ECA & HTI & MSL & Total / Average \\
\hline Total water consumption & 453.535 & 468.617 & 423.494 & 397.289 & 424.167 & 467.479 & 2.634 .581 \\
Irrigation water consumption & 46.286 & 79.232 & 25.480 & 77.285 & 38.263 & 37.388 & 303.934 \\
\% Consumption irrigation & $10 \%$ & $17 \%$ & $6 \%$ & $19 \%$ & $9 \%$ & $8 \%$ & $12 \%$ \\
$\mathrm{~m}^{2}$ garden & 8.000 & 11.000 & 6.000 & 14.000 & 8.000 & 5.000 & 52.000 \\
Average daily consumption & 21 & 36 & 10 & 42 & 17 & 11 & 139 \\
$\mathrm{~L} / \mathrm{m}^{2}$ daily & 2,64 & 3,29 & 1,70 & 3,03 & 2,18 & 2,26 & 2,67 \\
\hline
\end{tabular}


To perform a simplified approximation of the consumption of irrigation, taking into account only the air temperature and not considering go their factors, such as the type of flora, the similarity of the gardens, or the rainfall of the islands, annual accumulated average being the lowest in both the Canary Islands and Spain at 100 $1 / \mathrm{m}^{2}$ year ${ }^{\beta}$. With the average data of the percentage of consumption for irrigation in respect to the maximum value of the monthly irrigation values of the hotels shown in Table 4, a linear regression to test their dependence on the temperature was performed, proving that its coefficient of determination is very high and hence their dependence very strong, as shown in Figure 2.

Given that the annual average for daily consumption is $2.67 \mathrm{l} / \mathrm{m} 2$, corresponding to $80 \%$ of the value of irrigation, the maximum value, $100 \%$, corresponds to $3.341 / \mathrm{m} 2$, which is the maximum value of daily irrigation. With the function calculated by linear regression, the function for calculating monthly consumption in litres for irrigation according to the surface area of the garden can be generated.

$W_{\text {irr }}=\left(3,34(0,0371 t-0,0152) A_{g}\right) d$

Where " $A$ " is the area of garden in $\mathrm{m}^{2}$, " $\mathrm{d}$ " is the number of days of the month of calculation and " $\mathrm{t}$ " the average monthly temperature in ${ }^{\circ} \mathrm{C}$ in the area where the hotel is situated on the islands.

With the consumption of water in swimming pools, which is another determinant factor in the cost of water, there are several variables involved in the daily renewal necessary to maintain the level of the swimming pools, which can be enumerated with the following factors: evaporation, leakage in the pool itself and the circuit, washing of filters, etc. Table 5 shows consumption data for hotel swimming pools, differentiating between the cold and heated pools. The importance of pool maintenance, which amounts to $13 \%$ of the water consumption of a hotel, can be checked, without taking into account maintenance of hot tubs, which are affected by the rules of legionella $\mathrm{\beta}$ and which mark the minimum amount of water maintenance of this type. It has been studied for this type of thermal pools 9 . Daily consumption of water for swimming pool maintenance, generically speaking, takes a daily value of $2.42 \%$, with a standard deviation of $0.5 \%$, which is considered sufficient to perform an approximate calculation for the water consumption of swimming pools, according to volume.

As hotel swimming pools use fresh water, this expense for modelling calculations of total water consumption has to be taken into account. In order to calculate approximations of monthly swimming pool water consumption in $\mathrm{m} 3$, taking into account the volume, the following function can be used to simulate an approximation of consumption:

$$
W p_{m}=\left(0,0242 V_{T p}\right) d
$$

Where " $\mathrm{V}_{\mathrm{TP}}$ " is the total volume of cold-water swimming pools, heated pools and Spas in $\mathrm{m}^{3}$, " $\mathrm{d}$ " is the number of days of the month of the calculation.

Table 4. Average air temperature and percentage of monthly irrigation water consumption

\begin{tabular}{lccccccccccccc}
\hline UNIT & Jan & Feb & Mar & Apr & May & Jun & Jul & Aug & Sep & Oct & Nov & Dic & Average \\
\hline To & 17,9 & 17,9 & 18,9 & 20,2 & 21,7 & 23,2 & 24,8 & 25,5 & 24,9 & 23,8 & 21,3 & 19,1 & 17,9 \\
$\%$ irrigation & $63 \%$ & $69 \%$ & $72 \%$ & $83 \%$ & $78 \%$ & $92 \%$ & $94 \%$ & $100 \%$ & $93 \%$ & $80 \%$ & $78 \%$ & $70 \%$ & $80 \%$ \\
\hline
\end{tabular}
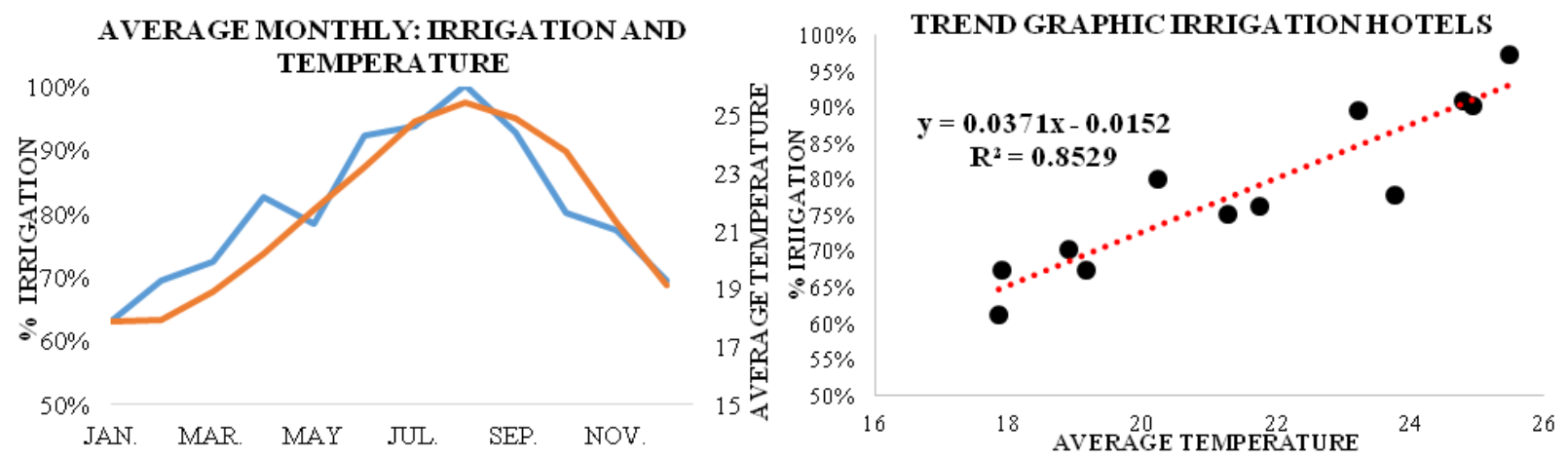

Figure 2. Average consumption of irrigation water and representation of the linear regression function. Source: Original. 
Table 5. Water consumption in recreational and climatized pools

\begin{tabular}{|c|c|c|c|c|c|c|c|c|}
\hline TYPE & & HPE & HT & ESA & ECA & HTI & MSL & TOTAL \\
\hline \multirow[t]{3}{*}{ Total Year } & Total water consumption & 453.535 & 468.617 & 423.494 & 397.289 & 424.167 & 467.479 & 2.634 .581 \\
\hline & Consumption water pools & 53.929 & 26.342 & 49.930 & 66.824 & 40.976 & 113.899 & 351.900 \\
\hline & $\%$ consumption pool & $12 \%$ & $6 \%$ & $12 \%$ & $17 \%$ & $10 \%$ & $24 \%$ & $13 \%$ \\
\hline \multirow[t]{3}{*}{ Cold pool } & Volume water pool $\mathrm{m}^{3}$ & 765 & 266 & 891 & 706 & 1.135 & 1.727 & 5.490 \\
\hline & Average daily consumption & 21 & 4 & 17 & 16 & 18 & 48 & 123 \\
\hline & $\%$ average daily consumption & $2,76 \%$ & $1,51 \%$ & $1,91 \%$ & $2,22 \%$ & $1,55 \%$ & $2,78 \%$ & $2,25 \%$ \\
\hline \multirow[t]{3}{*}{ Climatized pool } & Volume water pool $\mathrm{m}^{3}$ & 130 & 298 & 298 & 487 & 79 & 110 & 1.402 \\
\hline & Average daily consumption & 3 & 7 & 7 & 19 & 2 & 6 & 43 \\
\hline & $\%$ average daily consumption & $1,96 \%$ & $2,47 \%$ & $2,35 \%$ & $3,85 \%$ & $2,18 \%$ & $5,44 \%$ & $3,09 \%$ \\
\hline \multirow[t]{3}{*}{ Total } & Volume water pool $\mathrm{m}^{3}$ & 895 & 564 & 1.189 & 1.193 & 1.214 & 1.837 & 6.892 \\
\hline & Average daily consumption & 24 & 11 & 24 & 34 & 19 & 54 & 167 \\
\hline & $\%$ average daily consumption & $2,64 \%$ & $2,01 \%$ & $2,02 \%$ & $2,89 \%$ & $1,59 \%$ & $2,94 \%$ & $2,42 \%$ \\
\hline
\end{tabular}
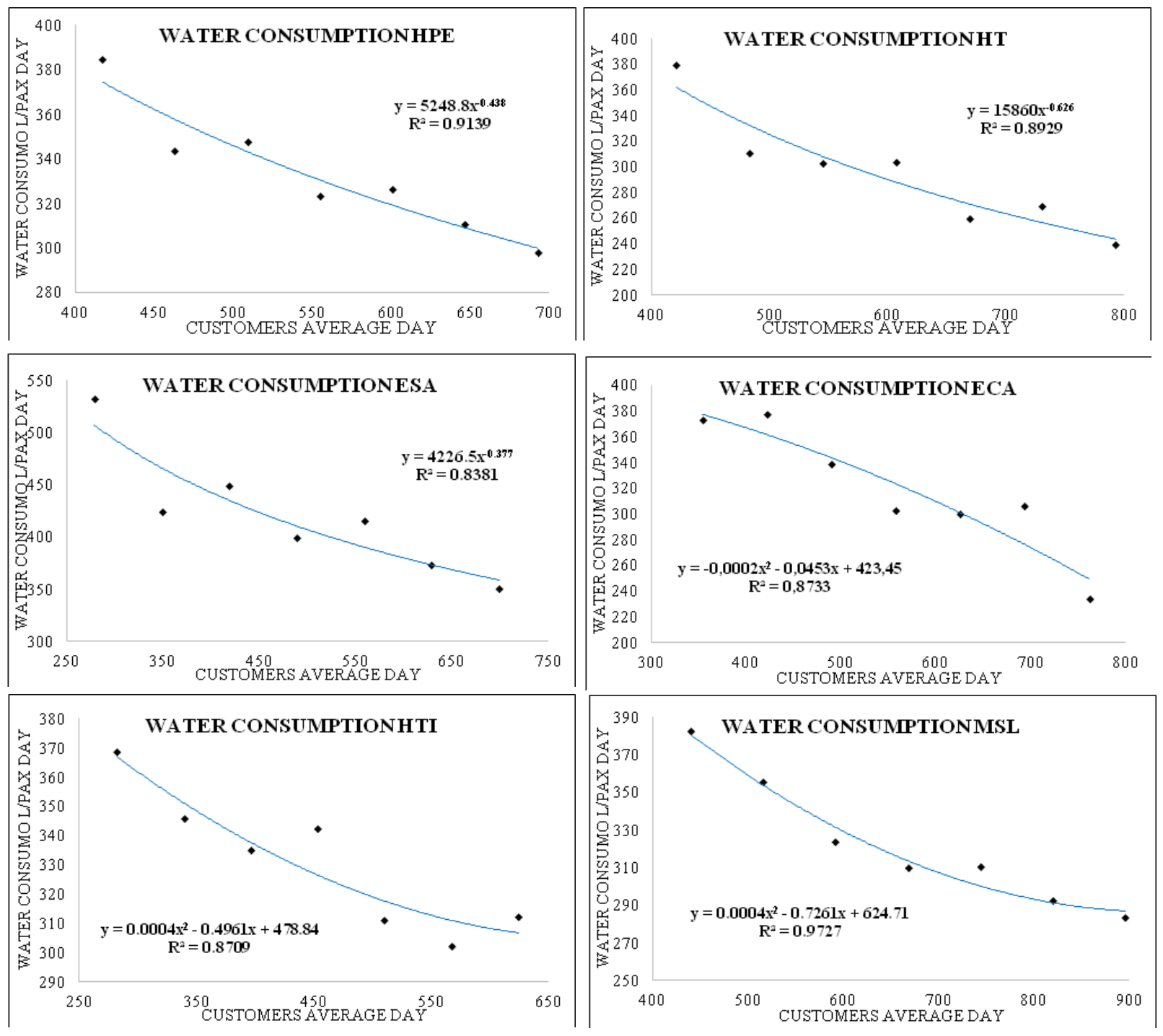

Figure 3. Characteristic function with the greatest correlation index for each hotel for different regression models for water consumption, without considering irrigation. Source: Original. 


\subsubsection{Water Consumption in Hotels without Irrigation}

Having established the average consumption from swimming pools and irrigation, the correlation calculations of different levels of water consumption of hotels-recalling that the consumption of irrigation has not been taken into account, but the consumption of pools has-were performed. The following graphs show the different average points calculated for each hotel, according to the daily occupancy rate and daily average water consumption in litres per guest. In Figure 3 each hotel represents the characteristic function with a greater correlation index and a greater determination coefficient $\mathrm{R}^{2}$ for different regression models.

Table 6 summarizes the calculation values of the functions of the investigated regression models, where the different values of the coefficient of determination can be checked, with the potential and polynomial correlation which best fit the graph. The increased potential of consumption is due to the declining number of guests. Since the minimum consumption of some facilities is independent of the number of guests, we consider the minimum fixed consumption to be maintained.

\subsection{Electricity Consumption}

Electricity in hotels is the main source of energy used in them, since most of the equipment and facilities work with this type of energy. Electricity consumption represents about $70 \%$ of the total energy consumption of hotels. In the hotels in this study, all electric power is supplied externally, not counting the establishments with any active generation or cogeneration system, so their external dependence is total. This external dependence clashes with the possibility of obtaining buildings with ZEB or nZEB, so it is necessary to model their consumption and check their behaviour according to occupancy rates, seeking alternatives to this external dependence through self-supply of electricity with different types of power generation systems based on renewable energy.

For comparison of electricity consumption, the use of water from the public supply or from the hotel's own desalination Sea Water Reverse Osmosis Plants (SWROP)

Table 6. Summary of functions and coefficient of determination of the different types of correlation for water consumption

\begin{tabular}{|c|c|c|c|c|}
\hline \multicolumn{2}{|c|}{ CORRELATION TYPE } & HPE & HT & ESA \\
\hline \multirow{10}{*}{ 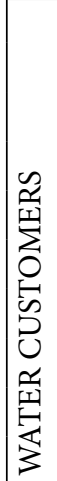 } & Linear & $y=-0,2687 x+483$ & $y=-0,3148 x+486$ & $y=-0,3466 x+590$ \\
\hline & Linear $\mathrm{R}^{2}$ & 0,8842 & 0,8496 & 0,7869 \\
\hline & Exponential & $y=517,53 e^{-8 E-04 x}$ & $y=552,06 e^{-0,001 x}$ & $y=619,13 e^{-8 E-04 x}$ \\
\hline & Exponential $\mathrm{R}^{2}$ & 0,9002 & 0,8758 & 0,8161 \\
\hline & Logarithmic & $y=-147,9 \ln (x)+1265,9$ & $y=-188,7 \ln (x)+1499,5$ & $y=-163,3 \ln (x)+1424,2$ \\
\hline & Logarithmic $\mathrm{R}^{2}$ & 0,9034 & 0,8784 & 0,8245 \\
\hline & Polynomial & $y=0,0006 x^{2}-0,8871 x+649,43$ & $y=0,0006 x^{2}-1,0462 x+698,32$ & $y=0,0006 x^{2}-0,8853 x+710,89$ \\
\hline & Polynomial $\mathrm{R}^{2}$ & 0,9083 & 0,8854 & 0,8162 \\
\hline & Potential & $\mathrm{y}=5248,8 \mathrm{x}^{-0,438}$ & $y=15860 x^{-0,626}$ & $y=4226,5 x^{-0,377}$ \\
\hline & Potential $\mathrm{R}^{2}$ & 0,9139 & 0,8929 & 0,8381 \\
\hline \multicolumn{2}{|c|}{ CORRELATION TYPE } & ECA & HTI & MSL \\
\hline \multirow{10}{*}{ 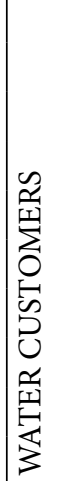 } & Linear & $y=-0,3142 x+494$ & $y=-0,1759 x+411$ & $y=-0,2056 x+460$ \\
\hline & Linear $\mathrm{R}^{2}$ & 0,8662 & 0,8380 & 0,9158 \\
\hline & Exponential & $y=556,66 e^{-0,001 x}$ & $y=419,72 e^{-5 E-04 x}$ & $y=487,92 e^{-6 E-04 x}$ \\
\hline & Exponential $\mathrm{R}^{2}$ & 0,8390 & 0,8377 & 0,9338 \\
\hline & Logarithmic & $y=-165,4 \ln (x)+1359,9$ & $y=-77,36 \ln (x)+801,65$ & $y=-135,2 \ln (x)+1198,2$ \\
\hline & Logarithmic $\mathrm{R}^{2}$ & 0,8403 & 0,8637 & 0,9554 \\
\hline & Polynomial & $y=-0,0002 x^{2}-0,0453 x+423,45$ & $y=0,0004 x^{2}-0,4961 x+478,84$ & $y=0,0004 x^{2}-0,7261 x+624,71$ \\
\hline & Polynomial $\mathrm{R}^{2}$ & 0,8733 & 0,8709 & 0,9727 \\
\hline & Potential & $y=8995,3 x^{-0,533}$ & $\mathrm{y}=1352,2 \mathrm{x}^{-0,232}$ & $\mathrm{y}=4582,4 \mathrm{x}^{-0,41}$ \\
\hline & Potential $\mathrm{R}^{2}$ & 0,8013 & 0,8591 & 0,9653 \\
\hline
\end{tabular}


has to be taken into account, which represent between $10 \%$ and $15 \%$ of hotels' total consumption. This can be seen in Table 7 of values from 2013, where the average energy consumption from desalinations about 4.77 $\mathrm{kWh} / \mathrm{m}^{3}$, taking into account the SWROP and pumping brackish or saltwater from a catch pit.
To perform the calculations for modelling the consumption of electricity, the consumption of SWROP are not considered, as there are hotels without desalination plants. The following graphs Figure 4 shows the different average points for electricity consumption calculated for each hotel according to the average daily occupancy rates

Table 7. Consumption of electrical energy for desalination in hotels, 2013

\begin{tabular}{lccccc}
\hline TYPE (2013) & HPE & HT & HTI & MSL & TOTAL \\
\hline ELECTRICITY & 2.830 .578 & 4.025 .026 & 3.045 .352 & 2.822 .006 & 12.722 .962 \\
DESALINATION & 357.115 & 391.600 & 292.212 & 420.801 & 1.461 .729 \\
\% Desalination & $13 \%$ & $10 \%$ & $10 \%$ & $15 \%$ & $11 \%$ \\
Desalinated water & 68.676 & 78.320 & 76.898 & 82.510 & 306.404 \\
Consumption & 5,20 & 5,00 & 3,80 & 5,10 & 4,77 \\
$\mathrm{kWh} / \mathrm{m} 3$ & & & & & \\
\hline
\end{tabular}
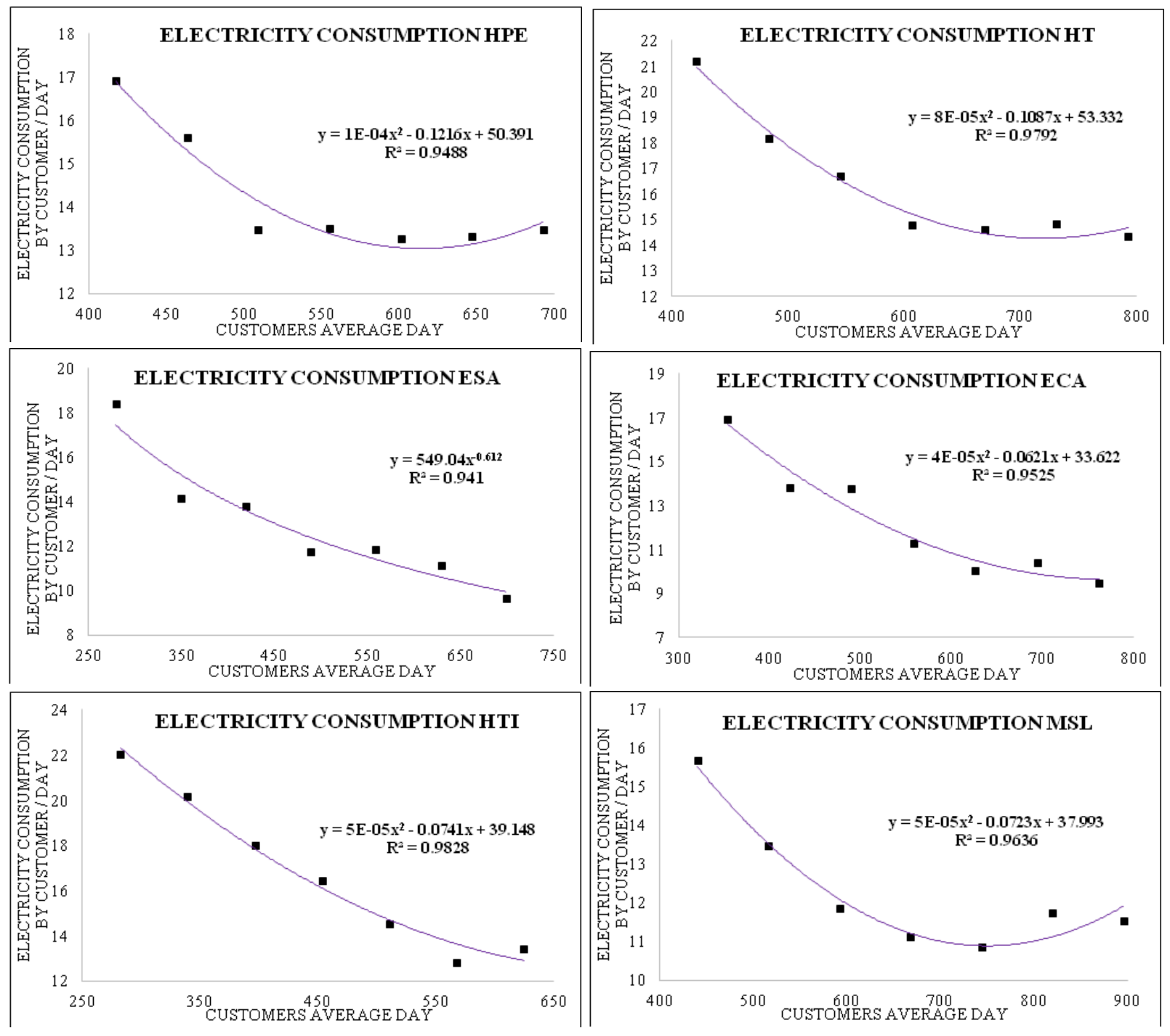

Figure 4. Characteristic function with the greatest correlation index for each hotel for different regression models for electricity consumption, without considering the desalination plant. Source: Original. 
and the average daily electrical energy consumption in $\mathrm{kWh}$ per guest. They represent in all the graphs the line of tendency according to the correlation function with greater determination coefficient $\mathrm{R}^{2}$.

Table 8 summarizes the calculations performed to obtain the functions of the regression models of consumption of electricity per customer per day, checking the different values of the coefficient of determination, which indicate the degree of correlation between data. The high correlation of the values of occupancy and consumption of electricity is tested, the polynomial correlation being the one which best fits in almost all cases, except in the case of ESA hotels.

\subsection{Energy Performance}

Hotels currently use multiple primary energy sources to meet their energy needs. To make comparisons, it is necessary to transfer such energy sources to a common unit of reference, in this case $\mathrm{kWh}$, according to the values of energy conversion given in Table 9 provided by the IDAE ${ }^{10-46}$

The main types of energy used in hotels are:

- Electricity: generic use in all facilities. Between 60 and $75 \%$ of energy.

- LPG: kitchens, DHW heating and acclimatization of pools. Between 10 and $30 \%$ of energy.

- Diesel: DHW heating and acclimatization of pools. Between 10 and $30 \%$ of energy.

Table 8. Summary of functions and coefficient of determination of the different types of correlation for energy consumption

\begin{tabular}{|c|c|c|c|c|}
\hline \multicolumn{2}{|l|}{ TYPE } & HPE & HT & ESA \\
\hline \multirow{10}{*}{ 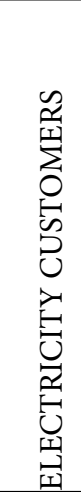 } & Linear & $y=-0,0117 x+21$ & $y=-0,0169 x+27$ & $y=-0,0174 x+21$ \\
\hline & Linear $\mathrm{R}^{2}$ & 0,6536 & 0,7952 & 0,8605 \\
\hline & Exponential & $y=21,941 e^{-8 E-04 x}$ & $y=29,509 e^{-1 E-03 x}$ & $\mathrm{y}=24,094 \mathrm{e}^{-0,001 \mathrm{x}}$ \\
\hline & Exponential $\mathrm{R}^{2}$ & 0,6578 & 0,8195 & 0,9083 \\
\hline & Logarithmic & $\mathrm{y}=-6,692 \ln (\mathrm{x})+56,414$ & $\mathrm{y}=-10,36 \ln (\mathrm{x})+82,512$ & $\mathrm{y}=-8,278 \ln (\mathrm{x})+63,854$ \\
\hline & Logarithmic $\mathrm{R}^{2}$ & 0,7167 & 0,8607 & 0,9169 \\
\hline & Polynomial & $y=1 E-04 x^{2}-0,1216 x+50,391$ & $y=8 E-05 x^{2}-0,1087 x+53,332$ & $y=4 E-05 x^{2}-0,0562 x+30,182$ \\
\hline & \begin{tabular}{|l|} 
Polynomial R ${ }^{2}$ \\
\end{tabular} & 0,9488 & 0,9792 & 0,9260 \\
\hline & Potential & $y=240,9 x^{-0,449}$ & $y=760,9 x^{-0,603}$ & $y=549,04 x^{-0,612}$ \\
\hline & Potential $\mathrm{R}^{2}$ & 0,7202 & 0,8802 & 0,9410 \\
\hline \multicolumn{2}{|l|}{ TYPE } & ECA & HTI & MSL \\
\hline \multirow{10}{*}{ 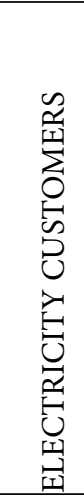 } & Linear & $y=-0,0172 x+22$ & $y=-0,0275 x+29$ & $y=-0,0079 x+18$ \\
\hline & Linear $\mathrm{R}^{2}$ & 0,8859 & 0,9505 & 0,5869 \\
\hline & Exponential & $y=25,85 e^{-0,001 x}$ & $y=34,496 e^{-0,002 x}$ & $y=18,283 e^{-6 E-04 x}$ \\
\hline & Exponential $\mathrm{R}^{2}$ & 0,9126 & 0,9555 & 0,5861 \\
\hline & Logarithmic & $\mathrm{y}=-9,445 \ln (\mathrm{x})+71,674$ & $\mathrm{y}=-12,07 \ln (\mathrm{x})+90,206$ & $\mathrm{y}=-5,493 \ln (\mathrm{x})+47,902$ \\
\hline & Logarithmic $\mathrm{R}^{2}$ & 0,9293 & 0,9748 & 0,6821 \\
\hline & Polynomial & $y=4 E-05 x^{2}-0,0621 x+33,622$ & $y=5 E-05 x^{2}-0,0741 x+39,148$ & $y=5 E-05 x^{2}-0,0723 x+37,993$ \\
\hline & Polynomial R ${ }^{2}$ & 0,9525 & 0,9828 & 0,9636 \\
\hline & Potential & $y=1320,6 x^{-0,747}$ & $y=1235,8 x^{-0,71}$ & $y=182,49 x^{-0,417}$ \\
\hline & Potential $\mathrm{R}^{2}$ & 0,9418 & 0,9657 & 0,6803 \\
\hline
\end{tabular}

Table 9. Factors of conversion for combustible fuel energy in kWh. Source: IDAE

\begin{tabular}{lcc}
\hline COMBUSTIBLE TYPE & \multicolumn{2}{c}{ ENERGY CONVERSION FACTORS } \\
\hline DIESEL OIL & 10,28 & $\mathrm{KWh} / \mathrm{L}$ \\
LPG PROPANE & 12,75 & $\mathrm{kWh} / \mathrm{kg}$ \\
Wood Pellets (humidity<15\%) & 5,01 & $\mathrm{kWh} / \mathrm{kg}$ \\
Pellets generally & 4,57 & $\mathrm{kWh} / \mathrm{kg}$ \\
\hline
\end{tabular}


Table 10. Summary of energy consumption from hotels in study from 2011

\begin{tabular}{|l|c|c|c|c|c|c|c|}
\hline ENERGY TYPE & HPE & HT & ESA & ECA & HTI & MSL & TOTAL \\
\hline ELECTRICITY & 3.596 .447 & 3.855 .650 & 2.394 .797 & 2.372 .912 & 2.978 .048 & 3.021 .838 & 18.219 .692 \\
\hline$\%$ Electricity & $72 \%$ & $68 \%$ & $70 \%$ & $63 \%$ & $62 \%$ & $67 \%$ & $67 \%$ \\
\hline LPG PROPANE & 1.372 .410 & 1.801 .014 & 194.081 & 272.582 & 906.895 & 307.224 & 4.854 .206 \\
\hline \% LPG propane & $28 \%$ & $32 \%$ & $6 \%$ & $7 \%$ & $19 \%$ & $7 \%$ & $18 \%$ \\
\hline DIESEL OIL & & & 822.400 & 1.099 .960 & 544.316 & 441.989 & 2.908 .664 \\
\hline \% Diesel oil & $0 \%$ & $0 \%$ & $24 \%$ & $29 \%$ & $11 \%$ & $10 \%$ & $11 \%$ \\
\hline THERMAL SOLAR & & & & & 350.842 & 739.200 & 1.090 .042 \\
\hline \% Thermal solar & $0 \%$ & $0 \%$ & $0 \%$ & $0 \%$ & $7 \%$ & $16 \%$ & $4 \%$ \\
\hline TOTAL ENERGY & 4.968 .857 & 5.656 .664 & 3.411 .278 & 3.745 .454 & 4.780 .100 & 4.510 .250 & 27.072 .603 \\
\hline
\end{tabular}

- Biomass: DHW heating and acclimatization of pools. Usually replacing LPG or diesel oil boilers in the same proportion, representing between 10 and $30 \%$ of energy.

- Thermal Solar: DHW heating and acclimatization of pools. Between 5 and $20 \%$ of energy.

Table 10 lists the different types of energy consumption in 2011, where the importance of electricity consumption can be seen. Renewable energy does not yet represent a significant percentage of consumption. From 2014, HTI diesel cats switched to biomass, which means an increase to $15 \%$ of renewable energy, this value being too low to obtain ZEB or nZEB buildings.

Figure 5 can be used to check the distribution of energy consumption in percentages by energy type for the year 2011, highlighting the importance of electricity consumption in hotels, where it represents $67 \%$ of total consumption, and the low importance of renewable energies in that year, representing only $4 \%$ from thermal solar energy.

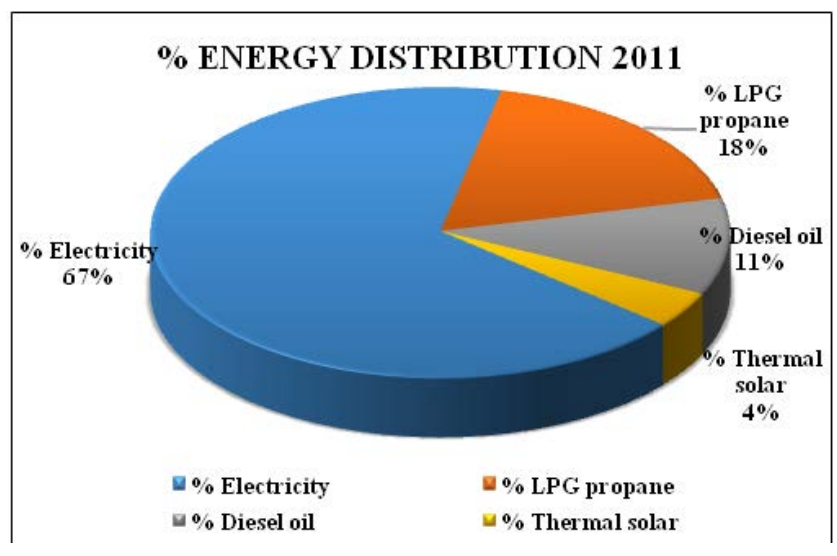

Figure 5. Distribution of energy consumption in hotels study 2011. Source: Original.
In the calculations of the modelling of energy consumption, the consumption of desalination plants is not taken into account. Figure 6 shows the average points of energy consumption calculated for each hotel according to the average daily occupancy rates and the average daily consumption of energy per guest in kWh. The line of tendency is represented in all the graphs, according to the correlation function with the greatest determination coefficient $\mathrm{R}^{2}$.

Table 11 summarizes the calculations performed to obtain the functions of regression models of total energy consumption per customer per day, checking the different values of the coefficient of determination, which indicates the degree of correlation between the data. The high correlation values of occupancy and energy consumption is tested, the polynomial correlation being that which best fits consumption, except in the case of ESA, where it is the potential, and HTI, where it is the exponential.

\subsection{Study Mathematical Model}

Since the hotels in this study have different maximum capacities, the same number of clients translates to different percentages of occupancy. This requires changing the ratios of consumption per guest to consumption by percentage of occupancy, since, in this way, we can compare the occupancy rates of different hotels in balance with the conditions of occupancy. With the amount of data from all the hotels, it was found that the occupancy intervals used and on which we have data, cover occupancy values of between $45 \%$ and $120 \%$. Once we divided by intervals and filtered them, we performed the correlation calculations for the calculated mean values.

With the calculations performed, Figure 9 was generated, representing the midpoints for consumption of 

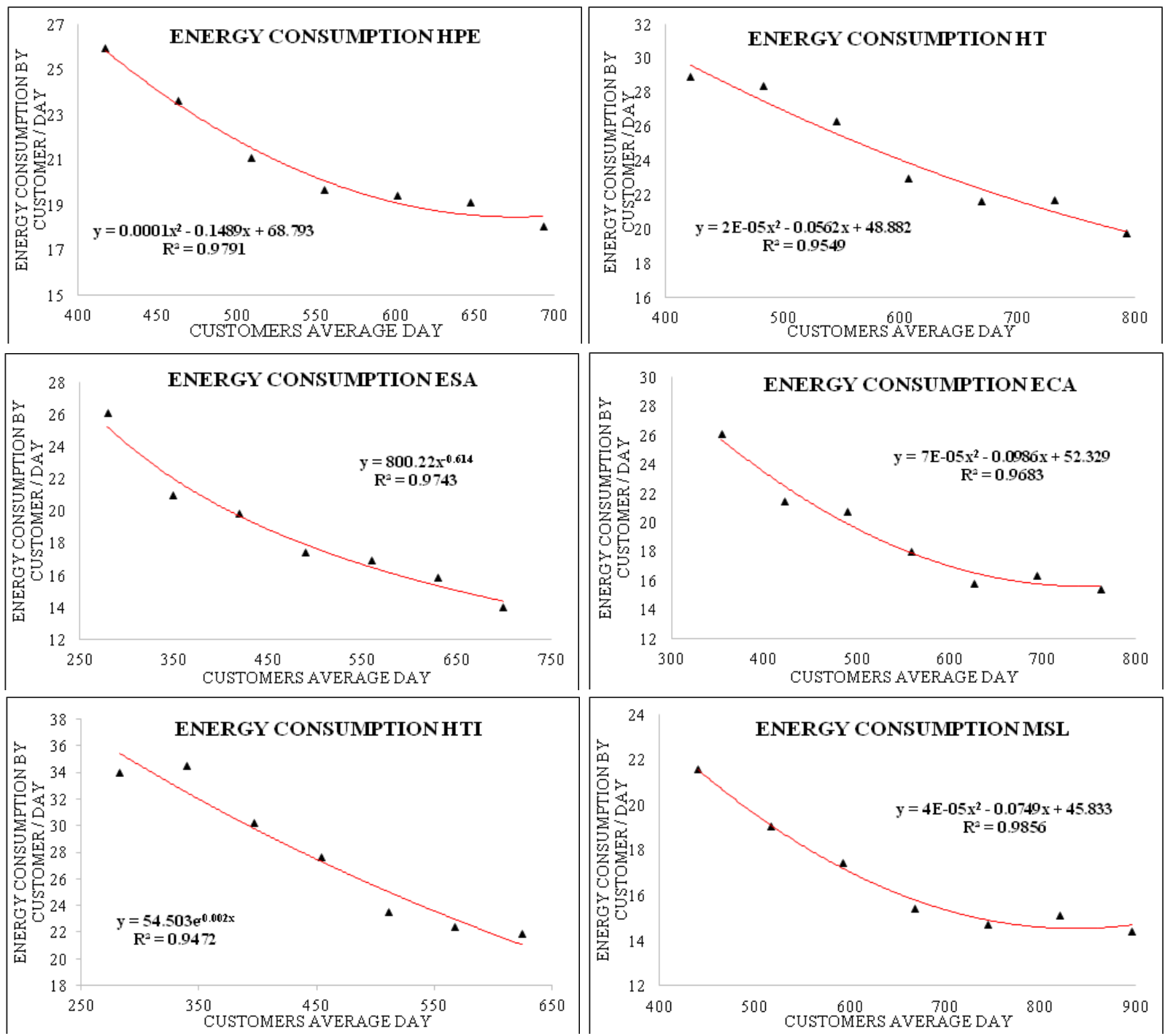

Figure 6. Characteristic function with the greatest correlation index for each hotel for the different regression models for total energy consumption, without considering desalination plants. Source: Original.

water, electricity and energy for all the hotels combined. The line of tendency is represented in all the graphs, according to the correlation function with the greatest determination coefficient $\mathrm{R}^{2}$.

Table 12 shows the calculations performed to obtain the functions for the regression models of water, electricity and energy are summarized. A strong correlation was found between the consumption of water and energy, which fits almost perfectly with the potential function. The best fit for consumption of electricity is a type of polynomial function, although the potential function also has a high degree of correlation.

After verifying the strong correlation between the systems of polynomial regression in electricity and potential in water and total energy, the suitability of these functions can be confirmed, comparing the actual values of the averages for the hotels with values of the functions generated by the regression models. All the regression models have been compared on the same graph, calculating the values of the functions from an occupancy rate of $1 \%$ to $140 \%$, which is shown in Figure 7. It can also be seen how the values of the regression functions have been paired for values of between $40 \%$ to $120 \%$ occupancy, for which, among these values - which are where the average occupancy rates for the hotels are usually found - the mean values of supplies with any of the functions can be approximated, although taking into account that the optimum fit has to use the potential or 
Table 11. Summary of functions and coefficient of determination of the different types of correlation for total energy consumption. Source: Original.

\begin{tabular}{|c|c|c|c|c|}
\hline \multicolumn{2}{|c|}{ TYPE } & HPE & HT & ESA \\
\hline \multirow{10}{*}{ 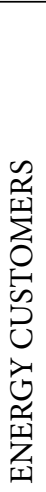 } & Linear & $y=-0,0267 x+36$ & $y=-0,0262 x+40$ & $y=-0,0252 x+31$ \\
\hline & Linear $\mathrm{R}^{2}$ & 0,8834 & 0,9452 & 0,9073 \\
\hline & Exponential & $y=41,405 e^{-0,001 x}$ & $y=46,225 e^{-0,001 x}$ & $y=35,024 e^{-0,001 x}$ \\
\hline & Exponential $\mathrm{R}^{2}$ & 0,9072 & 0,9514 & 0,9488 \\
\hline & Logarithmic & $y=-14,84 \ln (x)+114,53$ & $y=-15,49 \ln (x)+123,22$ & $y=-11,9 \ln (x)+91,935$ \\
\hline & Logarithmic $\mathrm{R}^{2}$ & 0,9226 & 0,9523 & 0,9566 \\
\hline & Polynomial & $y=0,0001 x^{2}-0,1489 x+68,793$ & $y=2 E-05 x^{2}-0,0562 x+48,882$ & $y=5 E-05 x^{2}-0,0748 x+42,206$ \\
\hline & Polynomial R ${ }^{2}$ & 0,9721 & 0,9549 & 0,9615 \\
\hline & Potential & $y=1571,9 x^{-0,686}$ & $y=1386 x^{-0,635}$ & $y=800,22 x^{-0,614}$ \\
\hline & Potential $\mathrm{R}^{2}$ & 0,9408 & 0,9511 & 0,9743 \\
\hline \multicolumn{2}{|c|}{ TYPE } & ECA & HTI & MSL \\
\hline \multirow{10}{*}{ 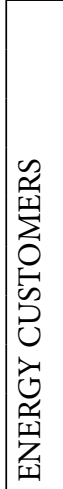 } & Linear & $y=-0,0247 x+33$ & $y=-0,0421 x+47$ & $y=-0,0151 x+27$ \\
\hline & Linear $\mathrm{R}^{2}$ & 0,8807 & 0,9405 & 0,8549 \\
\hline & Exponential & $y=37,91 e^{-0,001 x}$ & $y=54,503 e^{-0,002 x}$ & $y=29,695 e^{-9 E-04 x}$ \\
\hline & Exponential R $^{2}$ & 0,9085 & 0,9472 & 0,8758 \\
\hline & Logarithmic & $y=-13,61 \ln (x)+104,75$ & $y=-18,17 \ln (x)+138,32$ & $y=-10,04 \ln (x)+81,849$ \\
\hline & Logarithmic $\mathrm{R}^{2}$ & 0,9323 & 0,9354 & 0,9153 \\
\hline & Polynomial & $y=7 E-05 x^{2}-0,0986 x+52,329$ & $y=3 E-05 x^{2}-0,0672 x+52,174$ & $y=4 E-05 x^{2}-0,0749 x+45,833$ \\
\hline & Polynomial $\mathrm{R}^{2}$ & 0,9683 & 0,9442 & 0,9856 \\
\hline & Potential & $y=1402,2 x^{-0,685}$ & $y=1464,7 x^{-0,655}$ & $y=683,88 x^{-0,574}$ \\
\hline & Potential $\mathrm{R}^{2}$ & 0,9472 & 0,9326 & 0,9286 \\
\hline
\end{tabular}
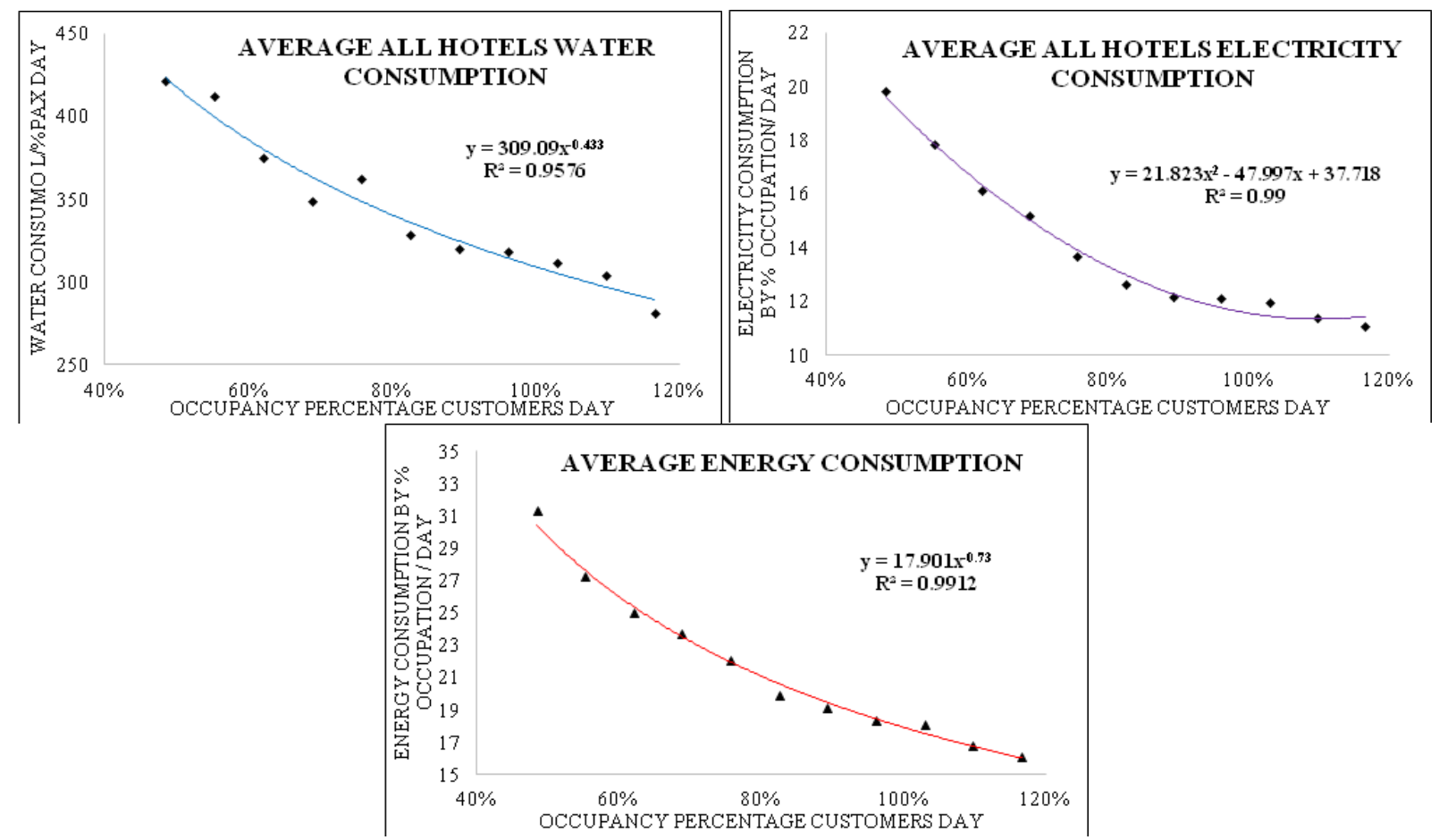

Figure 7. Characteristic function with the greatest correlation index for the consumption of water, electricity and energy of all hotels. Source: Original. 
Table 12. Summary of functions and coefficient of determination of the different types of correlation for consumption of water, electricity and energy. Source: Original.

\begin{tabular}{lccc}
\hline TYPE & \multicolumn{3}{c}{ DATA FOR ALL HOTELS } \\
\cline { 2 - 4 } & WATER CUSTOMERS & ELECTRICITY CUSTOMERS & ENERGY CUSTOMERS \\
\hline Linear & $\mathrm{y}=-190,38 \mathrm{x}+500,91$ & $\mathrm{y}=-11,988 \mathrm{x}+23,879$ & $\mathrm{y}=-20,312 \mathrm{x}+38,362$ \\
Linear $\mathrm{R}^{2}$ & 0,9247 & 0,8838 & 0,9257 \\
Exponential & $536,13 \mathrm{e}^{-0,547 \mathrm{x}}$ & $\mathrm{y}=27,163 \mathrm{e}^{-0,826 \mathrm{x}}$ & $\mathrm{y}=45,157 \mathrm{e}^{-0,919 \mathrm{x}}$ \\
Exponential $\mathrm{R}^{2}$ & 0,9412 & 0,9212 & 0,9647 \\
Logarithmic & $\mathrm{y}=-151,6 \ln (\mathrm{x})+309,16$ & $\mathrm{y}=-9,732 \ln (\mathrm{x})+11,762$ & $\mathrm{y}=-16,33 \ln (\mathrm{x})+17,868$ \\
Logarithmic $\mathrm{R}^{2}$ & 0,9542 & 0,9476 & 0,9733 \\
Polynomial & $\mathrm{y}=180,19 \mathrm{x}^{2}-487,69 \mathrm{x}+615,18$ & $\mathrm{y}=21,823 \mathrm{x}^{2}-47,997 \mathrm{x}+37,718$ & $\mathrm{y}=27,706 \mathrm{x}^{2}-66,027 \mathrm{x}+$ \\
& & & 55,931 \\
Polynomial $\mathrm{R}^{2}$ & 0,9547 & 0,9900 & 0,9882 \\
Potential & $\mathrm{y}=309,09 \mathrm{x}^{-0,433}$ & $\mathrm{y}=11,803 \mathrm{x}^{-0,664}$ & $\mathrm{y}=17,901 \mathrm{x}^{-0,73}$ \\
Potential $\mathrm{R}^{2}$ & 0,9576 & 0,9700 & 0,9912 \\
\hline
\end{tabular}
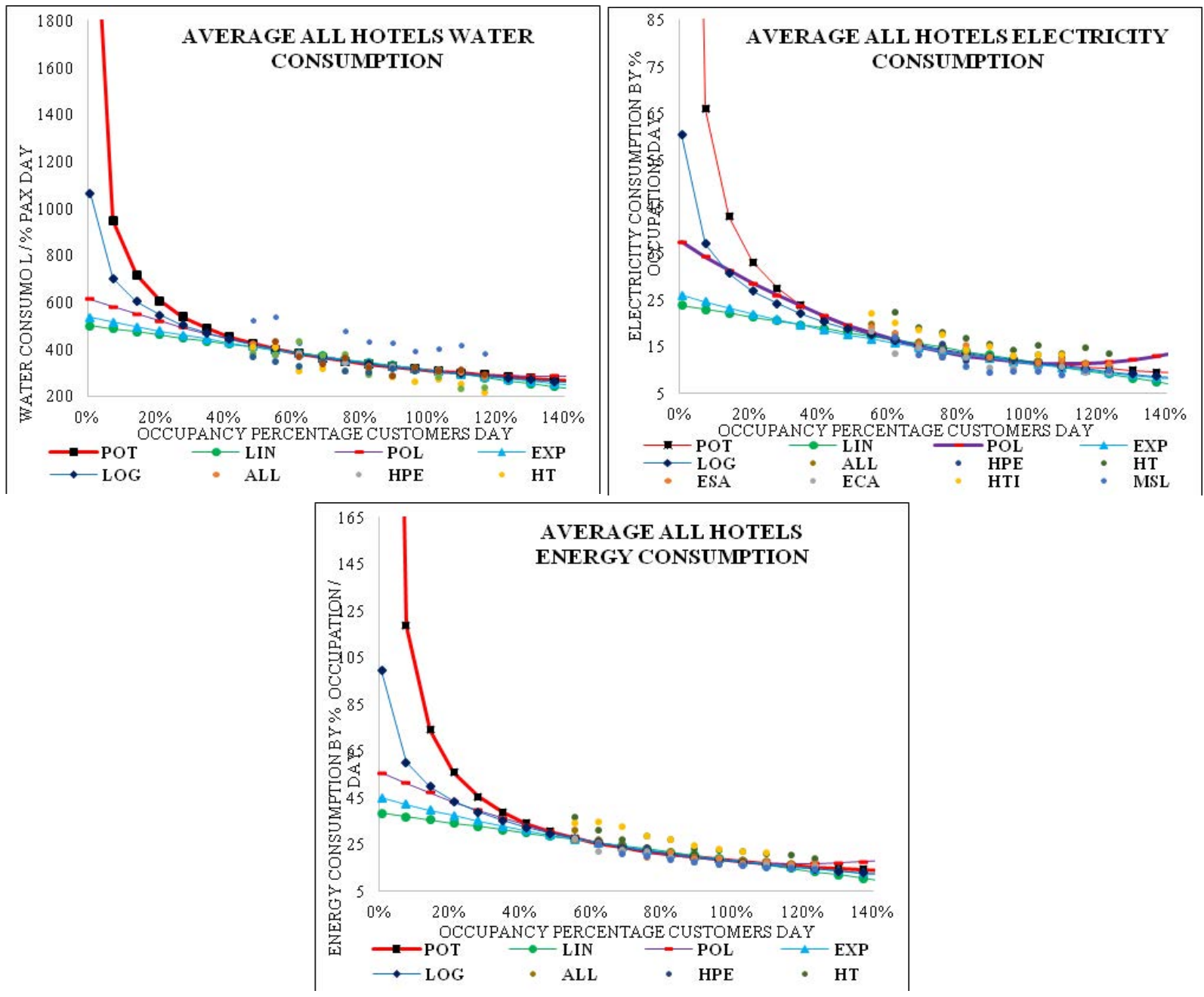

Figure 8. Representation of regression functions between 1 and 140\% occupancy with respect to the midpoints of water, electricity and energy consumption of the different hotels. 
polynomial function.

\section{Results and Discussion}

It was found that the values of the midpoints for the levels of consumption of the hotels approximately fit the values of the calculated functions. The next step was to check that the calculated mean values for all hotels fit with the generated function in order to demonstrate the validity of the models calculated for the average occupancy values, which range in a generic sense between $30 \%$ and $130 \%$. Figure 9 represents functions of water, electricity and energy appear.

In reviewing the representation of the functions, it was found that the average data fits the graphs generated, so the potential function can be used for the approximation of the values of water and energy consumption, and the polynomial for electricity consumption for a group of four-star hotels with similar characteristics such as those studied here. consumption, taking into account the average daily occupancy, air temperature for water consumption for irrigation and desalinated water production for specific consumption, are summarized as follows:

- Water

Consumption without irrigation:

$W_{T T}=\left(309,09 x^{-0,433}\right) d$

Consumption with irrigation:

$W_{\text {TTirr }}=\left(\left(309,09 x^{-0,433}\right)+\left(3,34 A_{g}(0,0371 t-0,0152)\right)\right) d$

- Electricity

Consumption without irrigation:

$E l_{T T}=\left(21,832 x^{2}-47,997 \mathrm{x}+37,718\right) d$

Consumption desalination SWROP without irrigation:

$E l_{T T d w}=\left(\left(21,832 x^{2}-47,997 \mathrm{x}+37,718\right)+\left(W_{T T} C_{d w}\right)\right) d$

Consumption desalination SWROP with irrigation:

$E l_{\text {TTdwirr }}=\left(\left(21,832 x^{2}-47,997 \mathrm{x}+37,718\right)+\left(W_{T T i r r} C_{d w}\right)\right) d$

The functions that bring us the values of monthly
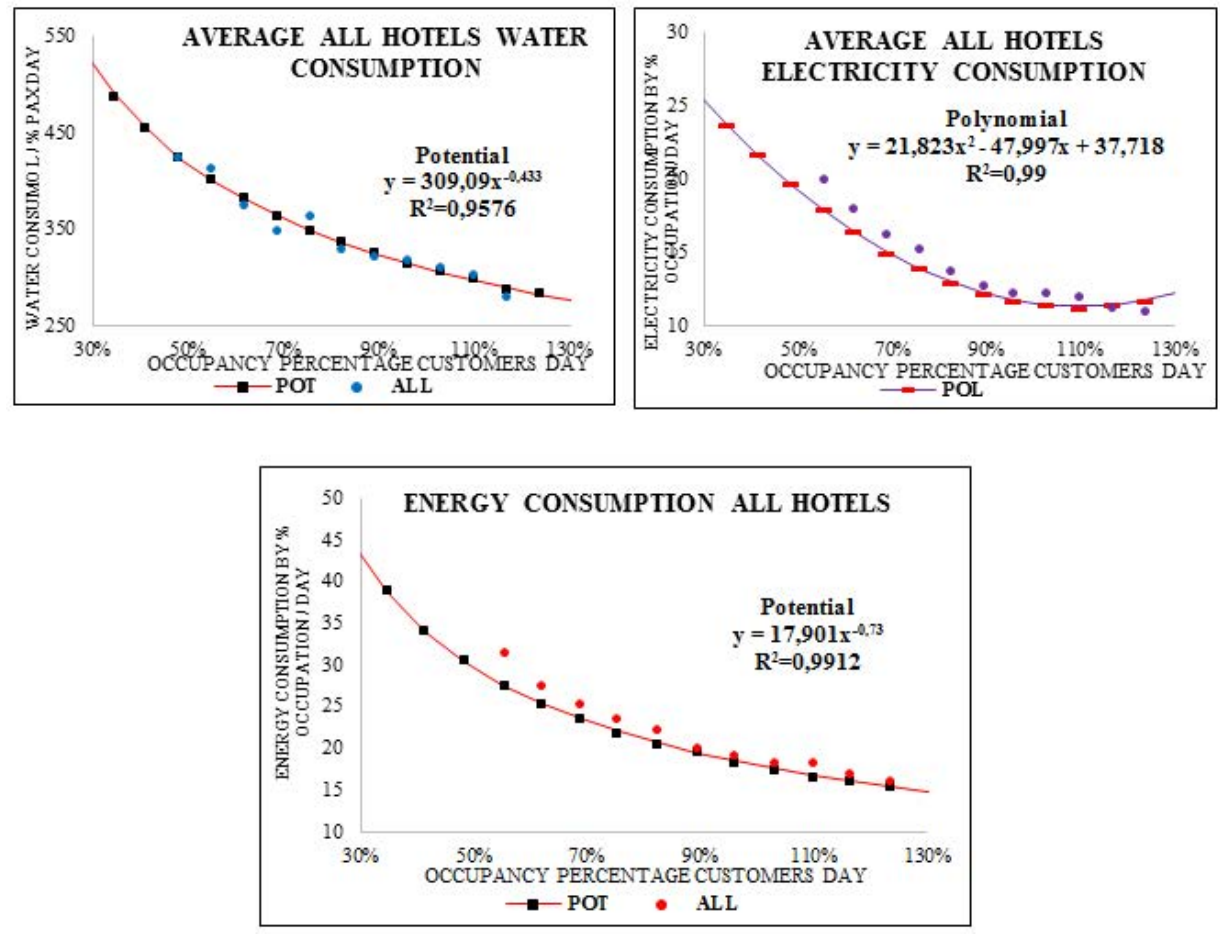

Figure 9. Representation of regression functions between 30 and 130\% occupancy with respect to the midpoints of the average consumption of water, electricity and energy calculated for all hotels. 
- Energy:

Consumption without irrigation:

$E_{T T}=\left(17,901 x^{-0,73}\right) d$

Consumption desalination SWROP without irrigation:

$E_{T T d w}=\left(\left(17,901 x^{-0,73}\right)+\left(W_{T T} C_{d w}\right)\right) d$

Consumption desalination SWROP with irrigation:

$E_{T T d w i r r}=\left(\left(17,901 x^{-0,73}\right)+\left(W_{T T i r r} C_{d w}\right)\right) d$

Where " $x$ " is the percentage of average occupancy, " $\mathrm{C}_{\mathrm{dw}}$ " is the specific consumption of the plant in $\mathrm{kWh} / \mathrm{m}^{3}$ of water generated, "A " is the surface area of gardens, " $\mathrm{g}$ " is the number of days of calculation and " $t$ " the average temperature in the area where the hotel is located on the islands.

The main reasons for the increase in specific consumption, even with decreasing occupancy, are related to the need for facilities to be in place and consuming energy or water at the hotel, with or without guests, since the sectorization of equipment or systems cannot be carried out in most of the hotels studied, implying that the minimum consumption is always due to the ongoing maintenance of facilities.

\section{Conclusions}

Using the method described, a model of the typical consumption of water, electricity, and energy for a hotel in a determined segment, which may be reproduced for any other hotel in the sector, was obtained, thus making it possible to check and compare consumption. With the application of statistical functions and correlation, optimum consumption models can be generated for a group of homogeneous hotels, taking into account that the more data obtained, the more reliable will be the generated models. The basic procedure followed and demonstrated leaves the field open to more complex and precise research, applicable to any type of supply for hotels.

With the different correlation models studied, it has been found that, in most cases, the potential or polynomial models is applicable, with very little difference between the correlation coefficients. The calculated values, from which we can consider similar approximations for both models, are between 40 and 120\% occupancy, being that lower or higher occupancy rates have very large differences from which no equivalent can be made.

The peculiarity of hotels with a desalination seawater reverse osmosis plants SWROP where energy consumption is directly related to water consumption and influence the type of irrigation used - is studied. This proves the need to improve the efficiency of the desalination plants SWROP in reducing water consumption and irrigation in order to achieve a proportional energy reduction in the hotels.

The use of renewable energy is highly unrepresented in the hotels from the study. This can and should be improved, mainly through using renewable energy sources for domestic hot water (DHW), which represents $22 \%$ of energy consumption in hotels. In this way, external energy dependence could be reduced.

This study leaves open the way to further investigation into the importance of hotel occupancy rates, with the carbon footprint generated by energy consumption being due to the activity of tourist accommodation, as well as the importance of water desalination in hotels in the Canary Islands, which is a determinant factor in the consumption of energy.

By comparing the different methods and systems for energy efficiency and developing the method studied, improvements can be simulated for application in facilities in order to compare the most optimal and effective models to be adopted, verifying this as hotels get closer to energy independence and achieving the objective of becoming ZEB or nZEB hotels.

\section{References}

1. UNWTO-UNEP. Climate Change and Tourism: Responding to Global Challenge. Madrid; 2008.

2. European Union. Directive 2010/31/EU of the parliament and of the council of 19 May 2010 on the energy performance of buildings (recast). Journal of the European Union. 2010; 153:13-35.

3. Kraus M, Kubeckova D. Airtightness of energy efficient buildings. GSTF International Journal of Engineering Technology. 2013 Aug; 2(2):74-80.

4. European Union. Directive 2012/27/EU of the European Parliament and of the Council of 25 October 2012 on energy efficiency, amending Directives 2009/125/EC and 2010/30/ EU and repealing Directives 2004/8/EC and 2006/32/EC Text with EEA relevance. Journal of the European Union. 2012; 315:1-56.

5. Zigurs A, Sarma U. Implementation of the energy efficiency directive: Opportunities and challenges. Latvian Journal of Physics and Technical Sciences. 2016; 52(6):1- 10.

6. Exeltur. Impactur Canarias 2014 - Study of the economic 
impact of tourism in the Canary Islands. Las Palmas Gran Canarias. 2015.

7. Santana JS, Godenau D. Tourism migrations and labour markets in the Canary Islands. Atlantis Magazine. 2015 Oct; 6:69-99.

8. ISTAC. Canary Islands Institute of Statistics. Tourism Survey. 2015.

9. Employment, Industry and Trade Counselling. Government of the Canary Islands. Energy Yearbook of the Canary Islands 2014. Las Palmas Gran Canarias. 2016.

10. Diaz SD, Cabrera EG, Calero AM, et al. Evaluation of potential technologies to reduce the pollution of the Canary Islands. Tenerife: University of La Laguna; 2011.

11. Carbon Trust. Hospitality, Saving Energy without Compromising Service. London; 2015.

12. Karagiorgas M, Drosou V, Tsoutsos Th. Solar energy and RES for the tourism sector. International Conference: RES for Island: RES and RUE for Islands, Sustainable Energy SolutionsLarnaka (Cyprus); 2004 Aug 30-31.

13. Moia-Pol A, Karagiorgas M, Coll-Mayor D, Martinez-Moll V, Riba-Romeva C. Evaluation of the energy consumption in Mediterranean Islands hotels: Case study of the Balearic Islands Hotels. International Conference on Renewable Energies and Power Quality; Palma de Mallorca. 2006 Apr.

14. Directorate General of Industry and Energy of the Government of the Canary Islands. Pilot project on the characterization of the end uses of energy in different types of consumers in the Canary Islands. Tenerife: University of La Laguna; 2007.

15. Chong H, Ricaurte EE. Hotel sustainability benchmarking tool 2015: Energy, water and carbon. Cornell Hospitality Reports. 2015 Jul; 5(9):6-11.

16. Hotel Energy Solutions. Hotel Energy Solutions: Fostering Innovation to Fight Climate Change - Public Report. Hotel Energy. Madrid; Solutions Project Publications; 2011.

17. Hotel Business Association of Madrid and Hotel Technological Institute (ITH). Benchotel Mark Madrid. Tool Energy Management in Hotels. Madrid; 2009.

18. Spanish Confederation of Hotels and tourist accommodations and Hotel Technological Institute (ITH). Benchotel Mark Canary Island. Tool Energy Management in Hotels. Madrid; 2007.

19. Priyadarsini R, Xuchao W, Eang LS. A study on energy performance of hotel buildings in Singapore. Energy and Buildings. 2009; 41(12):1319-34.

20. Wang JC. A study on the energy performance of hotel buildings in Taiwan. Energy and Buildings. 2012; 49:268-75.

21. Farrou I, Kolotroni M, Santamorius M. A method for energy classification of hotels: A case-study of Greece. Energy and Buildings. 2012; 55:553-62.

22. Bohdanowicz P, Martinac I. Determinants and benchmarking of resource consumption in hotels. Case study of Hilton International and Scandic in Europe. Energy and Buildings. 2007; 39(1):82-95.

23. Vicente MAC. Obtaining the tourist water demand curve for Acapulco, Guerrero. Observatory of the Latin American Economy. 2011; 143:1-28.

24. Izquierdo GE, Zabaleta AP, Perez LVV. Modelling of water and energy consumption in sun and beach hotels. Tourism and Cultural Heritage Magazine. 2014; 12(4):807-18.

25. Gossling S. Global environmental consequences of tourism. Global Environmental Change. 2002 Dec; 12(4):283-302.

26. NH Hotel Group. Annual Report 2014. Corporate Responsibility Report. Madrid; 2015.

27. Riu Hotels Y Resort. Achievements Corporate Social responsibility. Palma de Mayorca; 2014.

28. Sturges AH. The choice of a class interval Case I Computations involving a single. Journal of the American Statistical Association. 1926; 21:65-6.

29. Abdi H. Least-squares. Book Chapters: The SAGE Encyclopedia of Social Science Research Methods. Thousand Oaks, California: Sage Publications; 2004. p. 792-5.

30. Pearson K. On the criterion that a given system of deviations from the probable in the case of the correlated systems of variables is such that it can be reasonably supposed to have arisen from random sampling. Philosophical Magazine. 1900; 50(302):157-75.

31. Zou KH, Tuncali K, Silverman SG. Correlation and simple linear regression. RSNA Radiology. 2003 Jun; 227(3):61728.

32. Rodriguez EM. Frequent errors in the interpretation of the coefficient of linear determination. Legal and Economic Yearbook Escurialense. 2005; 38:315-32.

33. Couto MAG. Climatic atlas of the Canary Islands, Madeira and Azores archipelagos. Temperature and rainfall 19712010. Ed. State Agency of Meteorology. Ministry of Agriculture, Food and Environment. Madrid; 2012.

34. Spanish Ministry of the Presidence. Royal Decree 1620/2007 of 7 December 2007 where is regulated the legal regime for reuse of purified waste waters. Madrid; 2007.

35. Paranychianakis NV, Salgot M, Snyder SA, Angelakis AN. Water reuse in EU states: Necessity for uniform criteria to mitigate human and environmental risks. Critical Reviews in Environmental Science and Technology. 2015; 45(13):1409-68.

36. Spanish Ministry of the Presidence. Royal Decree 140/2003 of 7 February by which health criteria for the quality of water intended for human consumption are established. Madrid; 2003.

37. State Agency of Meteorology. Short guide to climate in Spain. Directorate of Production and Infrastructures. Ver 3. Madrid; 2012.

38. Spanish Ministry of the Presidence. Royal Decree $865 / 2003$ of 4 July which established hygiene criteria for the prevention and control of Legionnaires' disease. Madrid; 2003.

39. Walczak MW, Burkowska-But A, Brzezinska MS, et al. Distribution of Legionella pneumophila in thermal pools. Clean-Soil Air Water. 2016; 44(5):532-7.

40. IDAE. Calorific Values of the Main Energy Sources. Madrid; 2014. 
41. Jana A, Chandra B. Mediating role of customer satisfaction in the mid-market hotels: An empirical analysis. Indian Journal of Science and Technology. 2016 Jan; 9 (1):1-16.

42. Sundaram KM, Kumar RS, Krishnakumar C, Sugavanam KR. Fuzzy logic and firefly algorithm based hybrid system for energy efficient operation of three phase induction motor drives. Indian Journal of Science and Technology. 2016 Jan; 9(1):1-5.

43. Vijayan K, Raaza A. A novel cluster arrangement energy efficient routing protocol for wireless sensor networks. Indian Journal of Science and Technology. 2016 Jan; 9(2):1-9.

44. Rengarajan A, Rajasekaran S, Siramdasu H, Insozhan N. A novel method for energy effectiveness by employing adaptive node coverage region. Indian Journal of Science and Technology. 2016 Jan; 9(2):1-6.

45. Priya D, Arunarasi J, Mary AA. Efficient energy and power consumption of 3-D chip multiprocessor with NUCA architecture. Indian Journal of Science and Technology. 2016 Jan; 9(2):1-6.

46. Thiriveni GV, Ramakrishnan M. Distributed clustering based energy efficient routing algorithm for heterogeneous wireless sensor networks. Indian Journal of Science and Technology. 2016 Jan; 9(3):1-6. 